\title{
O SISTEMA DE CULTIVO E A ESTRUTURA DO SOLO EM CAFEZAL. PARTE II ( $\left.{ }^{1}\right)$
}

\author{
GASTÃo MORAES DA SILVEIRA $\left({ }^{2,3,5}\right)$, e SERGIO AUGUSTO HIROAKI KURACHI $\left({ }^{4,5}\right)$
}

\begin{abstract}
RESUMO
Foram verificadas as modificaçoes estruturais ocorridas no solo das ruas de um cafezal, pelo emprego de diferentes métodos de cultivo, em experimento instalado em Latossolo Roxo, no munićpio de Analândia (SP). As porcentagens de distribu içáo das partículas dentro de classes de tamanho e o diâmetro médio dos agregados do solo foram comparados para os diferentes métodos de cultivo. Após nove anos, de 1973 a 1982, constatou-se diferença significativa quanto ao diâmetro médio dos agregados, pelo emprego da roçadeira e pelos demais métodos. Constatou-se ainda que o diâmetro médio das partículas aumentou com o emprego da roçađeira, enquanto o uso da grade provocou diminuiçăo. O maior percentual médio acumulado das classes de agregados correspondeu ao emprego da roçadeira. $\mathbf{O}$ grau de compactação foi também objeto de estudo, usando-se a densidade como parâmetro para estimálo. Os valores de densidade foram excessivamente dispersos, não permitindo a avaliação dos efeitos dos diversos tratamentos na compactaç̃o do solo.
\end{abstract}

Termos de indexaçāo: mecanização agrícola; maquinária agricola; máquinas de cultivo; cultivo mecanizado; sistema de cultivo; cultura cafeeira.

$\left({ }^{1}\right)$ Parte I: Ver SILVEIRA et alii, 1977/78. Recebido para publicação em 26 de janeiro de 1984.

( $\left.{ }^{2}\right)$ Seção de Máquinas đe Movimentação do Solo, Instituto Agronômico (IAC), Caixa Postal 28 , 13100 - Campinas (SP).

$\left({ }_{4}^{3}\right)$ Atualmente, na Diretoria da Divisāo de Engenharia Agrícola, IAC.

$\left({ }_{5}^{4}\right)$ Seção de Projetos e Materiais, IAC.

( ${ }^{5}$ ) Com bolsa de suplemen taçäo do CNPq. 


\section{INTRODUÇÃO}

A capina manual de ervas daninhas em cafezal é tarefa que traz sérios problemas ao agricultor por diversas razðes: quantidade, qualidade, disponibilidade e custo da mão-de-obra que absorve. Permanecendo na cultura, as ervas daninhas concorrem em água e nutrientes, com sérios prejuízos ao cafeicultor. Assim, nas grandes e médias propriedades, vem ocorrendo a substituição gradativa da capina manual pelo cultivo mecanizado, mediante diversos tipos de máquinas agrícolas. $\mathrm{O}$ uso indiscriminado de equipamentos, dos diferentes princípios de funcionamento com que atuam ou em razão do intenso tráfego que promovem, pode acarretar problemas quanto à estruturação, compactação e erosão do solo, com efeitos na produção.

Referências bibliograficas estrangeiras sobre trabalhos semethantes são escassas. Foram encontrados artigos sobre estudos realizados no Quênia, por PEREIRA \& JONES (1954) e PEREIRA et alii (1964).

Assim, objetivou-se estudar as modificaçбes estruturais sofridas pelo solo com a utilização de diferentes métodos mecanizados de cultivo.

Os resultados ora apresentados correspondem ao período de nove anos de duração do experimento, isto é, desde o seu início, no ano agrícola de 1973/1974, até 1981/1982.

Por ser o café uma planta perene com produçôes em ciclos bienais, o trabalho prosseguirá por mais dois anos, até 1986.

\section{MATERIAL E MÉTODOS}

Os implementos utilizados nos experimentos foram: grade de discos, enxada rotativa, roçadeira e aplicador de herbicidas (SILVEIRA et alii, 1977/78).

Grade de discos: com duas seçōes dispostas em tandem (uma diante da outra), formando um ângulo entre si. Cada corpo é equipado com oito discos de $460 \mathrm{~mm}$ (18 polegadas) de diâmetro. Os discos da seção dianteira são recortados e, os da traseira, lisos. $O$ equipamento é centrado em relação ao trator e montado no sistema hidráulico de engate de três pontos; sua largura de corte é $1,30 \mathrm{~m}$ e, a profundidade de trabalho adotada, aproximadamente $0,07 \mathrm{~m}$. A grade de discos em pauta foi desenvolvida por SILVEIRA et alii (1977).

Enxada rotativa: o equipamento é acoplado ao sistema hidráulico de engate de três pontos, centrado em relação ao trator e acionado pela tomada de potência, a uma velocidade angular constante. A largura de corte do implemento é $1,00 \mathrm{~m}$. O eixo da enxada rotativa tem cinco flanges, sendo 
os dois laterais com três facas e, os três centrais, com seis facas cada um. Sua profundidade de trabalho é aproximadamente $0,07 \mathrm{~m}$.

Roçadeira: é deslocada em relação ao trator, de maneira a permitir o corte das ervas daninhas junto ao tronco da árvore, embaixo da "saia" do pé de café, e apresenta as seguintes características: largura de corte: $1,30 \mathrm{~m}$; deslocamento: $0,25 \mathrm{~m}$ à esquerda em relação ao trator e rotação das facas: $1.100 \mathrm{rpm}$. Esta roçadeira foi desenvolvid a por SILVEIRA (1975).

Aplicador de herbicida: empregou-se um pulverizador tracionado pelo trator e acionado pela tomada de potência. O herbicida, Paraquat, foi utilizado na dosagem de 2,5 litros por hectare.

O ensaio está instalado em latossolo roxo, na Fazenda Santa Elisa, no município de Analândia (SP), em terreno com cerca de $8 \%$ de declividade. O café cultivar Mundo-Novo, plantado no espaçamento de 4,00 x $2,80 \mathrm{~m}$, com duas plantas por cova, tinha, na instalação do ensaio, três anos e meio de idade.

A modificação da estrutura do solo está sendo avaliada pela distribuição dos agregados em classes de tamanho, a qual reflete satisfatoriamente as modificaçóes sofridas pelo solo em face dos diferentes métodos de cultivo (PEREIRA et alii, 1964) e através do diâmetro médio aritmético dos mesmos. A amostragem é feita numa profundidade de 0 a $10 \mathrm{~cm}$, abrindo-se covas e raspando-se uma das paredes até que se obtenha uma quantidade de material de cerca de 1,5 a 2,0kg. Coletam-se quatro amostras em cada parcela de 48 plantas, duas de cada lado.

Também a compactação do solo causada por passagens sucessivas de máquinas é estudada no presente trabalho. Para sua avaliaçđo o método empregado é o do anel volumétrico, determinando-se a densidade do solo. $\mathrm{O}$ anel volumétrico é uma peça de dimensठes padronizadas que permite sempre a retirada do mesmo volume de solo, no caso $50 \mathrm{~cm}^{3}$. A amostragem em cada parcela de 48 plantas é realizada na camada superficial, em quatro pontos por onde passou a roda do trator, sendo dois de um lado e dois do outro em relação à linha dos cafeeiros. Em cada ponto, são retirados dois anéis, num total de oito por parcela.

O delineamento experimental é de blocos ao acaso, com cinco tratamentos e seis repetições. Cada parcela compõe-se de uma linha de café com 48 plantas, e o implemento trabalha nas ruas adjacentes a cada linha. Assim, entre duas linhas ateis consecutivas, há uma bordadura, que é cultivada de cada um dos lados com implementos diferentes. Os tratamentos sao aplicados somente nas ruas; nas linhas, entre plantas, o cultivo é feito com enxada manual. 
As médias do diâmetro médio de agregados, durante o período, foram utilizadas para fazer a comparação entre os tratamentos pela aplicação do teste de Tukey.

\section{RESULTADOS E DISCUSSOES}

\subsection{Agregados do solo}

Os dados do quadro 1 relacionam-se às classes de agregados, refletindo as modificaçбes sofridas pelo solo depois da passagem dos implementos. Pelos valores médios das porcentagens de distribuição das partículas dentro das classes de tamanho de agregados, nota-se o seguinte: com a roçadeira, as partículas foram sempre maiores que com a grade de discos em todas as classes de tamanho nas quais foram separadas, mostrando que em ambos os casos os efeitos dos tratamentosi sobre os agregados foram opostos. Na roçadeira, o diâmetro médio aritmético dos agregados sofreu um aumento com o correr dos anos, enquanto na grade de discos houve uma diminuição, quando comparado com o efeito produzido pelo tratamento com a capina manual. Com respeito às propriedades físicas do solo, de acordo com RANZANI (1962), pode-se dizer que os efeitos do tratamento com roçadeira foram benéficos, tendo em vista o aumento produzido no tamanho dos agregados, cuja ação

QUADRO 1 - Distribuição de agregados em classes de tamanho, em latossolo roxo da Fazenda Santa Elisa, Analândia, SP. Médias do período de 1973/74 a 1981/82. Valores percentuais acumulados

Tratamento

Agregados no solo, de acordo com as classes de abertura de malhas $\left({ }^{1}\right)$

7 a $4 \mathrm{~mm} \quad 4$ a $2 \mathrm{~mm} \quad 2$ a $1 \mathrm{~mm} \quad 1$ a $1,5 \mathrm{~mm} \quad 0,50$ a $0,25 \mathrm{~mm}$

\begin{tabular}{lccccc}
\hline & \multicolumn{5}{c}{$\%$ \% } \\
\cline { 2 - 5 } $\begin{array}{l}\text { A. Capina manual } \\
\text { (testemunha) }\end{array}$ & 2,91 & 7,34 & 16,36 & 29,12 & 51,14 \\
B. Herbicida & 1,63 & 5,39 & 12,71 & 24,41 & 47,63 \\
C. Roçadeira & 3,40 & 10,06 & 20,70 & 32,86 & 54,08 \\
D. Grade de discos & 1,21 & 4,82 & 12,47 & 24,21 & 47,14 \\
E. Enxada rotativa & 2,08 & 6,35 & 15,11 & 28,32 & 50,49 \\
\hline
\end{tabular}

( $\left.{ }^{1}\right)$ Agregados estáveis em água. 
positiva, em solos de natureza argilosa, se reflete num melhor balanceamento entre as quantidades de macro e microporos, tornando mais adequada a sua capacidade de armazenamento de água e de ar, influindo nas relaçðes hídricas e trocas gasosas.

No quadro 2 são apresentados os diâmetros médios dos agregados, correspondentes ao periodo de duração do experimento. Como se pode verificar, o tratamento $\mathrm{C}$, roçadeira, apresentou o maior diâmetro médio aritmético, $0,47 \mu$. Isso parece indicar que, em virtude de não haver ação direta do equipamento sobre o solo, a matéria orgânica deixada contribua para maior agregação das partículas e, que, além disso, a cobertura produzida pelo material cortado reduza o efeito do impacto direto das chuvas, evitando a desagregação e a conseqüente erosão superficial do mesmo, hipótese formulada por PEREIRA \& JONES (1954).

\begin{tabular}{|c|c|c|c|c|c|c|c|c|c|c|}
\hline Tratamento & $1973 / 74$ & $1974 / 75$ & $1975 / 76$ & $1976 / 77$ & $1977 / 78$ & $1978 / 79$ & $1979 / 80$ & $1980 / 81$ & $1981 / 82$ & Medias( $\left({ }^{1}\right)$ \\
\hline A. Capina manual & $0.18 \pm 0,015$ & $0,25 \pm 0,035$ & $0,42 \pm 0,013$ & $0,40 \pm 0,024$ & $0,38 \pm 0,030$ & $0,55 \pm 0,068$ & $0,40 \pm 0,022$ & $0,39 \pm 0,025$ & $0,46 \pm 0,042$ & $0,38 \mathrm{~b}$ \\
\hline B. Herbicida & $0,17 \pm 0,011$ & $0,25 \pm 0,010$ & $0,42 \pm 0,044$ & $0,19 \pm 0,022$ & $0.25 \pm 0,018$ & $0,53 \pm 0,072$ & $0,36 \pm 0,015$ & $0.31 \pm 0.017$ & $0.30 \pm 0.020$ & $0.31 \mathrm{~b}$ \\
\hline C. Roçadein & $0,20 \pm 0,009$ & $0.38 \pm 0,041$ & $0,68 \pm 0,061$ & $0.38 \pm 0,025$ & $0,32 \pm 0,025$ & $0,82 \pm 0,104$ & $0,51 \pm 0,038$ & $0,46 \pm 0,049$ & $0,51 \pm 0,039$ & 0,47 a \\
\hline D. Grade de discos & $0.16 \pm 0,011$ & $0.24 \pm 0.026$ & $0.33 \pm 0.027$ & $0,17 \pm 0,010$ & $0.27 \pm 0,027$ & $0,40 \pm 0,026$ & $0,41 \pm 0,029$ & $0.37 \pm 0,022$ & $0.35 \pm 0,035$ & $0,30 \mathrm{~b}$ \\
\hline E. Enxada rotativa & $0,19 \pm 0,013$ & $0.25 \pm 0.035$ & $0,40 \pm 0.063$ & $0,30 \pm 0,011$ & $0,43 \pm 0,052$ & $0,48 \pm 0,038$ & $0,44 \pm 0,038$ & $0,39 \pm 0,018$ & $0,39 \pm 0,020$ & $0,36 \mathrm{~b}$ \\
\hline
\end{tabular}

(1) Valores seguidos da mesma ietra nao diferem estatisucamente, sendo o teste de Tukey, a nivel de 5\%. C. V. $=10,27 \%$.

Quanto aos demais tratamentos, embora não difiram significativamente, nota-se que o $\mathrm{D}$, grade de discos, é o que apresentou menor diâmetro médio aritmético, $0,30 \mu$, confirmando que o equipamento tem a tendência de pulverizar o solo, provocando efeito contrário ao da roçadeira. Segundo RANZANI (1962), a adaptação de terras às culturas exerce forte alteração no volume total de poros da camada arável do solo. Apesar de não se dispor de dados, há evidência em outros países duma redução de até $10 \%$ do volume total de poros, quando se compara o solo virgem cultivado (Lyon, Buckman \& Brady, 1952, citados por RANZANI, 1962). Essa redução da porosidade está associada com perdas de matéria orgânica, redução de atividades biológicas e conseqüente debilitação de importantes agentes de agregação do solo.

Com relação ao emprego da grade, outro efeito observado foi a erosão da camada superficial do solo, evidenciada pela formação de degraus junto às saias das plantas em todas as parcelas em que essa máquina foi empregada. 
Durante o período que ainda resta para o encerramento do trabalho, procurar-se-á determinar o teor de matéria orgânica presente nas amostras de solo coletadas para análise de agregados. Desse modo, é possível que os efeitos tanto da roçadeira como da grade possam ser associados à matéria orgânica, como agente de agregação ou de desagregação das partículas do solo, em função do seu teor.

\subsection{Compactação do solo}

Como os dados de densidade obtidos se mostraram demasiadamente dispersos, mascarando os possíveis efeitos dos tratamentos, não são apresentados, e a avaliação dos efeitos dos tratamentos deixou de ser objetivo deste trabalho.

\section{CONCLUSÕES}

a) O tratamento em que se empregou a roçadeira foi o que trouxe mais benefícios, com o aumento do diâmetro médio dos agregados e com a proteção que ofereceu contra a erosão.

b) A grade foi o equipamento que mais pulverizou o solo, e em todas as parcelas em que foi aplicada, constatou-se a formação de degraus junto às saias das plantas, provenientes da erosão superficial.

c) $\mathrm{O}$ método do anel volumétrico, além de ter-se mostrado excessivamente trabalhoso, não permitiu a análise dos dados obtidos em virtude de sua grande dispersão.

\section{SUMMARY}

\section{INFLUENCE OF WEED CONTROL METHODS ON THE SOIL STRUCTURE IN A COFFEE CROP}

Soil structure modifications were studied in a coffee crop, growing in a "Latossolo Roxo", at Analandia, State of São Paulo, Brazil. The effects of mechanical, chemical and hand hoeing methods of weed control were compared. Soil structure modifications were evaluated by the distribution of classes of aggregates and by the average diameter of soil particles. Also the soil compaction was considered and determined through the bulk density determinations. After nine years of experimentation, between 1973 and 1982, significant differences among the effects of the rotary shredder and the other treatments were observed, concerning the average diameter of soil particles. This result was confirmed by the average distribution percentages of particles in the classes of aggregates. Higher values for the average diameter of soil aggregates were observed when the rotary shredder was used, and lower values when the disc harrow was used. An evaluation of the several treatments effects was not possible, due to the dispersion of the bulk density values.

Index terms: agricultural mechanization; agricultural machinery; tillage machines; mechanical tillage; tillage system; coffee crop. 


\section{REFERENCIAS BIBLIOGRÁFICAS}

PEREIRA, H.C.; DAGG, M. \& HOSEGOOD, P.H. A tillage study in Kenya coffee; IV. The physical effects of constrating tillage treatments over thirty consecutive cultivation seasons. Empire Journal of Experimental Agriculture, 32: 125, 1964.

\& JONES, P.A. A tillage study in Kenya coffee. Part II. The effects of tillage practices on the structure of the soil. Empire Journal of Experimental Agriculture, 22:232, 1954.

RANZANI, G. Origem e desenvolvimento do solo: física do solo. Piracicaba, Departamento de Publicaçóes, Centro Acadêmico Luiz de Queiroz, ESALQ, 1962. Cap. 2, p.34-65.

SILVEIRA, G.M. da. Roçadeira deslocada. Campinas, Instituto Agronômico, 1975. 7p. (Circular, 43)

; FUJIWARA, M. \& KURACHI, S.A.H. Grade para capina de cafezal. Campinas, Instituto Agronômico, 1977. 5p. (Circular, 67)

; KURACHI, S.A.H. \& FUJIWARA, M. Comparação de métodos mecânicos e químicos, no controle de ervas daninhas em cafezal. O Agronômico, Campinas, 29/30: 137-148, 1977/78. 